01,11

\title{
Структура, термическая стабильность и транспортные свойства жаропрочного высокоэнтропийного сплава ZrTiHfNb
}

\author{
(C) Р.Е. Рыльцев ${ }^{1,2}$, С.Х. Эстемирова ${ }^{1,2}$, Д.А. Ягодин ${ }^{1}$, Е.В. Стерхов ${ }^{1}$, С.А. Упоров ${ }^{1,2}$ \\ ${ }^{1}$ Институт металлургии УрО РАН, \\ Екатеринбург, Россия \\ ${ }^{2}$ Уральский федеральный университет, \\ Екатеринбург, Россия \\ E-mail: rrylcev@mail.ru
}

Поступила в Редакцию 8 июля 2021 г.

В окончательной редакции 13 июля 2021 г.

Принята к публикации 16 июля 2021 г.

Проблема фазовой стабильности является одной из ключевых при исследовании высокоэнтропийных сплавов. Здесь мы рассматриваем этот вопрос для жаропрочного высокоэнтропийного сплава TiZrHfNb с ОЦК-структурой. Изучена эволюция структуры данного сплава в ходе изотермического отжига при $T=400^{\circ} \mathrm{C}$. Установлено, что исходный литой сплав состоит их двух сосуществующих ОЦК-фаз с близкими параметрами элементарной ячейки. Данное состояние в процессе отжига гомогенизируется; при этом сохраняется высоконапряженное наноструктурированное состояние и усиливается текстура. Теплопроводность сплава в интервале температур $20-400^{\circ} \mathrm{C}$ изменяется в интервале $8-16 \mathrm{~W} / \mathrm{m} \cdot \mathrm{K}$, что сравнимо по порядку величины с теплопроводностью сталей.

Ключевые слова: высокоэнтропийные сплавы, жаропрочные сплавы, фазовая стабильность.

DOI: 10.21883/FTT.2021.12.51652.29s

\section{1. Введение}

Высокоэнтропийными сплавами (ВЭС) называются многокомпонентные системы, состоящие как минимум из четырех элементов и имеющие состав, близкий к эквиатомному. Такие сплавы характеризуются четырьмя важными эффектами: высокая конфигурационная энтропия, замедленная диффузия элементов, сильные искажения кристаллической решетки и „коктейльный эффект“ (см., например, [1]). Исследование ВЭС является одним из наиболее прогрессивных и быстроразвивающихся направлений в современном материаловедении, причем интерес к ней неуклонно растет.

Одним из перспективных классов ВЭСов, являются жаропрочные ВЭСы - сплавы, включающие элементы из подгрупп титана (Ti, $\mathrm{Zr}, \mathrm{Hf})$, ванадия $(\mathrm{V}, \mathrm{Nb}, \mathrm{Ta})$ и хрома (Cr, Mo, W). Такие ВЭСы при высоких температурах обладают повышенной химической стойкостью и высокой механической прочностью [2].

Проблема стабилизации однофазного многокомпонентного твердого раствора на основе определенной структуры исторически является ключевой в данной области. На сегодняшний день синтезировано и изучено множество многокомпонентных сплавов из тугоплавких элементов. Большинство из них не являются однофазными материалами. Как правило, это двухфазные сплавы, где основная фаза представляет собой упорядоченный или неупорядоченный твердый раствор с объемно-центрированной кубической структурой (ОЦК). Второй фазой могут быть либо фазы Лавеса с кубической (C15) или гексагональной (C14) решеткой, либо твердые растворы на основе гексагональных плотноупакованных структур (ГПУ). Может наблюдаться также и иное структурное состояние. Например, авторы работы [3] синтезировали однофазный сплав $\mathrm{Ti}_{35} \mathrm{Zr}_{27.5} \mathrm{Hf}_{27.5} \mathrm{Nb}_{5} \mathrm{Ta}$ с орторомбической структурой, а в случае сплава $\mathrm{V}_{35} \mathrm{Ti}_{35} \mathrm{Fe}_{15} \mathrm{Cr}_{10} \mathrm{Zr}_{5}$ было выявлено наличие двух фаз с гранецентрированной кристаллической структурой (ГЦК) [4].

В большинстве случаев однофазные жаропрочные ВЭСы кристаллизуются в ОЦК-структуре. Среди них можно отметить следующие системы HfNbTaTiZr, NbTiVZr и $\mathrm{NbTiV}_{2} \mathrm{Zr}$ [5], HfNbTiZr [6], ZrNbTiVHf [7], NbReHfZrTi [8] и NbTaTiW [9]. В целом наблюдается общая тенденция: однофазный твердый раствор ВЭСов стабилен при высоких температурах (обычно более $1000 \mathrm{~K}$ ), когда конфигурационная энтропия играет ключевую роль, однако при низких температурах стабильным является многофазное состояние. Таким образом, актуальной задачей является создание однофазных ВЭСов, термодинамически стабильных в низкотемпературном диапазоне. Для жаропрочных ВЭСов это особенно актуально в контексте перспектив их использования в качестве материалов для нужд атомной промышленности [10]. В статье [10] подчеркивалось, что рабочий температурный интервал для данного приложения не превышает $400^{\circ} \mathrm{C}$.

В настоящей работе мы исследуем структуру, низкотемпературную термическую стабильность и транспортные свойства однофазного жаропрочного ВЭСа ZrTiHfNb. Существование однофазного твердого раствоpa c ОЦК-структурой в данной системе при низких 
температурах впервые было сообщено в [11], однако термическая стабильность и физические свойства изучены не были. Имея в виду результаты работы [10], мы ограничились отжигом сплава ZrTiHfNb при $T=400^{\circ} \mathrm{C}$, обозначенной ранее как предельной температурой для применения в качестве материалов для атомной промышленности [3].

\section{2. Синтез образцов и методика измерений}

Исходный сплав ZrTiHfNb был синтезирован из элементарных компонентов с чистотой не менее $99.99 \%$ методом электродуговой плавки в атмосфере очищенного гелия. Для достижения гомогенности образцы переплавлялись не менее 10 раз, с выдержкой в дуге при максимальной мощности не менее 1 min. Фазовое состояние образца контролировалось методом рентгеновского дифракционного анализа, а также с помощью оптического микроскопа. Поскольку изменение массы материала до и после сплавления не превысило 0.1 at \%, можно утверждать, что брутто-формула полученного сплава соответствовала эквиатомному составу ZrTiHfNb.

Рентгенографический анализ полученного образца показал формирование неупорядоченного твердого раствора с ОЦК-структурой. Термическим анализом установлено, что при нагреве этого образца до $400^{\circ} \mathrm{C}$ тепловые эффекты отсутствуют, что свидетельствует о том, что фазовых превращений в данном температурном диапазоне не происходит. Далее образец подвергался циклической термообработке в следующем режиме: 1) нагрев со скоростью $5 \mathrm{~K} / \mathrm{min}$ до $400^{\circ} \mathrm{C}$; 2) выдержка при $T=400^{\circ} \mathrm{C}$ в течение $\left.1-3 \mathrm{~h} ; 3\right)$ охлаждение со скоростью $5 \mathrm{~K} / \mathrm{min}$. Данный цикл повторялся три раза. Изотермическая выдержка при первых двух отжигах составила $1 \mathrm{~h}$, при третьем отжиге - $3 \mathrm{~h}$.

На всех указанных этапах термообработки производился калориметрический контроль происходящих в системе превращений с помощью прибора Netzsch STA 449C.

Фазовый состав и параметры микроструктуры образцов, подвергшихся термообработке, анализировали с помощью рентгеновского дифракционного анализа (дифрактометр Shimadzu XRD-7000) в пошаговом режиме в угловом диапазоне $2 \Theta=20-120^{\circ}, \Delta(2 \Theta)=0.03^{\circ}$, экспозиция в точке $3 \mathrm{sec}$. Анализ физического уширения линий проводилось методом Уильямсона-Холла, использующего выражение, учитывающее совместный вклад от малых ОКР (область когерентного рассеяния) и микродеформаций решетки: $\beta=4 \varepsilon \cdot \operatorname{tg} \Theta+\lambda_{x} /(D \cdot \cos \Theta)$, где $\beta$ - физическое уширение (rad), $\varepsilon-$ величина микроискажений (безразмерная величина), $\lambda_{x}$ - длина волны излучения $(\mathrm{nm}), \Theta-$ брэгговский угол $(\mathrm{rad}), D-$ средний размер ОКР (nm).

Температуропроводность $\alpha$ измерялась методом лазерной вспышки на приборе Netzsch LFA 457. Теплоемкость $C_{\mathrm{p}}$ вычислялась с использованием стандартного метода сравнения с использованием сплава инконель 600 в качестве эталона. Теплопроводность $\lambda$ вычислялась с помощью известного соотношения $\lambda=\alpha d C_{\mathrm{p}}$, где $d-$ плотность образца.

\section{3. Результаты и обсуждение}

Рентгеновским дифракционным анализом было установлено, что сплав TiZrHfNb, кристаллизуется в объемно-центрированной кубической структуре (ОЦК, пр. гр. $I m-3 m)$ (рис. 1). Однако брэгговские отражения (200) и (311) представлены в виде хорошо разрешенных дублетов (рис. 1). Это свидетельствует о наличии двух ОЦК-фаз (обозначены как bcc1 и bcc2 на рис. 1) с близкими межплоскостными расстояниями и различным химическим составом [12]. Неоднородность химического состава характерна при кристаллизации многокомпонентных сплавов, когда в первую очередь кристаллизуются более тугоплавкие компоненты, а периферийные слои и межзеренные пространства обогащены менее тугоплавкими компонентами.

Дифракционные максимумы исходного образца значительно уширены. Анализ их ширины (полная ширина на половине высоты) методом Уильямсона-Холла показал, что уширение вызвано как малыми размерами ОКР, так и наличием достаточно больших величин микродеформаций решетки (таблица). Малые размеры ОКР, вероятно, являются следствием большой концентрации дефектов кристаллической структуры, а также формирования наноструктурированного состояния в процессе быстрой кристаллизации. Высокоинтенсивная линия (200) является результатом текстуры.

После термической обработки структурно-фазовое состояние сплава не изменилось. Однако можно отметить некоторые существенные моменты.

Наиболее очевидным процессом в ходе термической обработки является гомогенизация сплава, т.е. более

Фазовый состав, параметр кристаллической структуры, средний размер областей когерентного рассеяния $(\langle D\rangle)$, среднее значение микродеформаций $(\langle\varepsilon\rangle)$ сплава TiZrHfNb, подвергшегося термоциклированию

\begin{tabular}{c|c|c|c|c}
\hline $\begin{array}{c}\text { Метод } \\
\text { обработки }\end{array}$ & $\begin{array}{c}\text { Фазовый } \\
\text { состав }\end{array}$ & $\begin{array}{c}a, \\
\mathrm{~nm}\end{array}$ & $\begin{array}{c}\langle D\rangle, \\
\mathrm{nm}\end{array}$ & $\langle\varepsilon\rangle \cdot 10^{-3}$ \\
\hline \multirow{2}{*}{$\begin{array}{c}\text { Исходный } \\
\text { слиток }\end{array}$} & ОЦК1 & $0.3457(1)$ & 63 & 4.0 \\
\cline { 2 - 5 } & ОЦК2 & $0.3438(8)$ & 63 & 3.6 \\
\hline \multirow{2}{*}{$\begin{array}{c}\text { (отжиг I) } \\
\text { (о00 } \mathrm{C}\end{array}$} & ОЦК1 & $0.3450(2)$ & 71 & 6 \\
\cline { 2 - 5 } & ОЦК2 & $0.3422(9)$ & 90 & 2.8 \\
\hline \multirow{2}{*}{\begin{tabular}{c} 
(отжиг II) \\
\cline { 2 - 5 }
\end{tabular}} & ОЦК2 & $0.3434(7)$ & 37 & 2.4 \\
\hline \multirow{2}{*}{$\begin{array}{c}T=400^{\circ} \mathrm{C} \\
(\text { отжиг III) }\end{array}$} & ОЦК1 & $0.3450(3)$ & 46 & 6 \\
\cline { 2 - 5 } & ОЦК2 & $0.3436(7)$ & 90 & -9
\end{tabular}



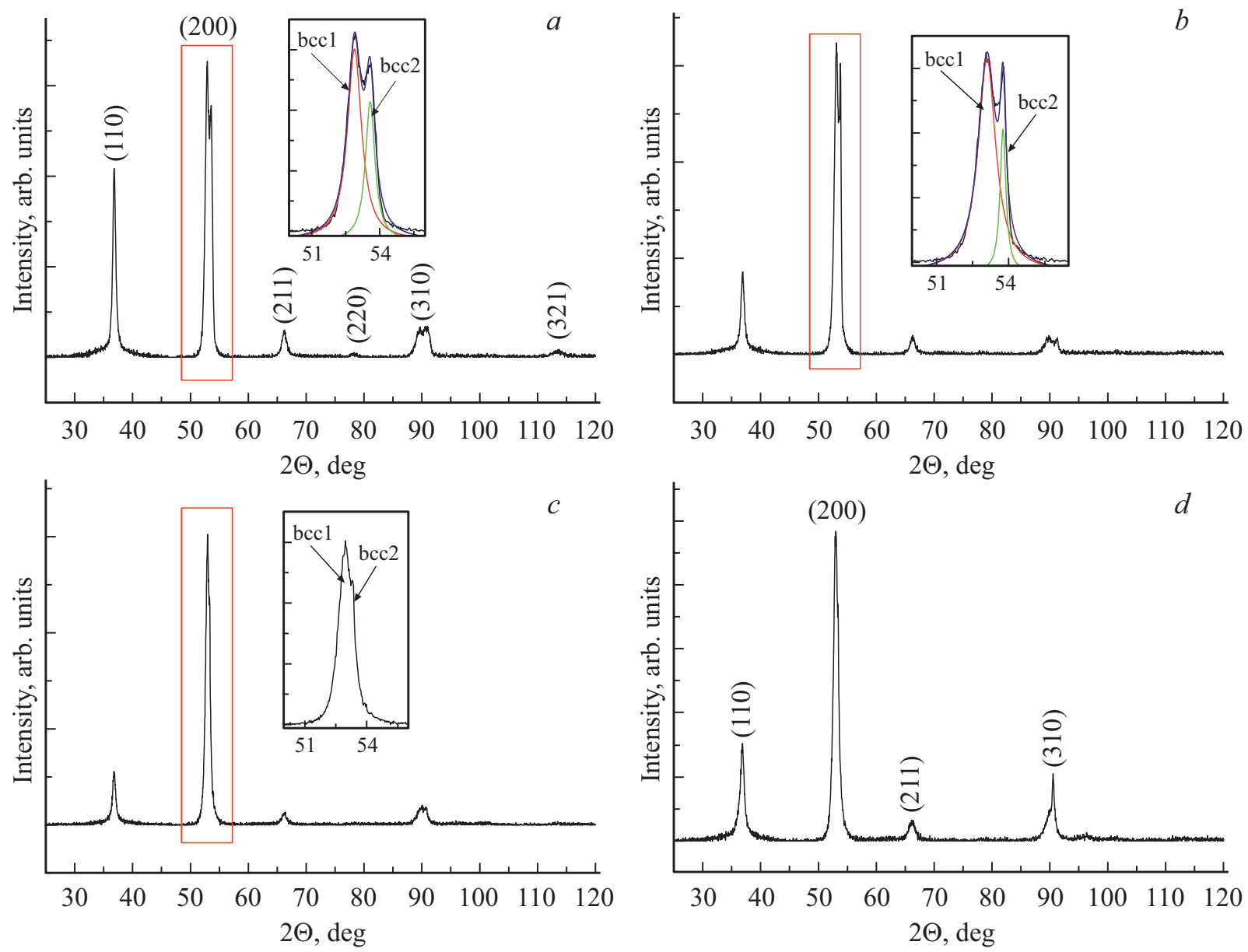

Рис. 1. Дифрактограммы исходного $(a)$ и отожженного при $T=400^{\circ} \mathrm{C}$ образца TiZrHfNb: $b, c, d-$ первый, второй и третий циклы соответственно. На вставках показан укрупненный фрагмент, показывающий расщепление линии (200) ОЦК-структуры.
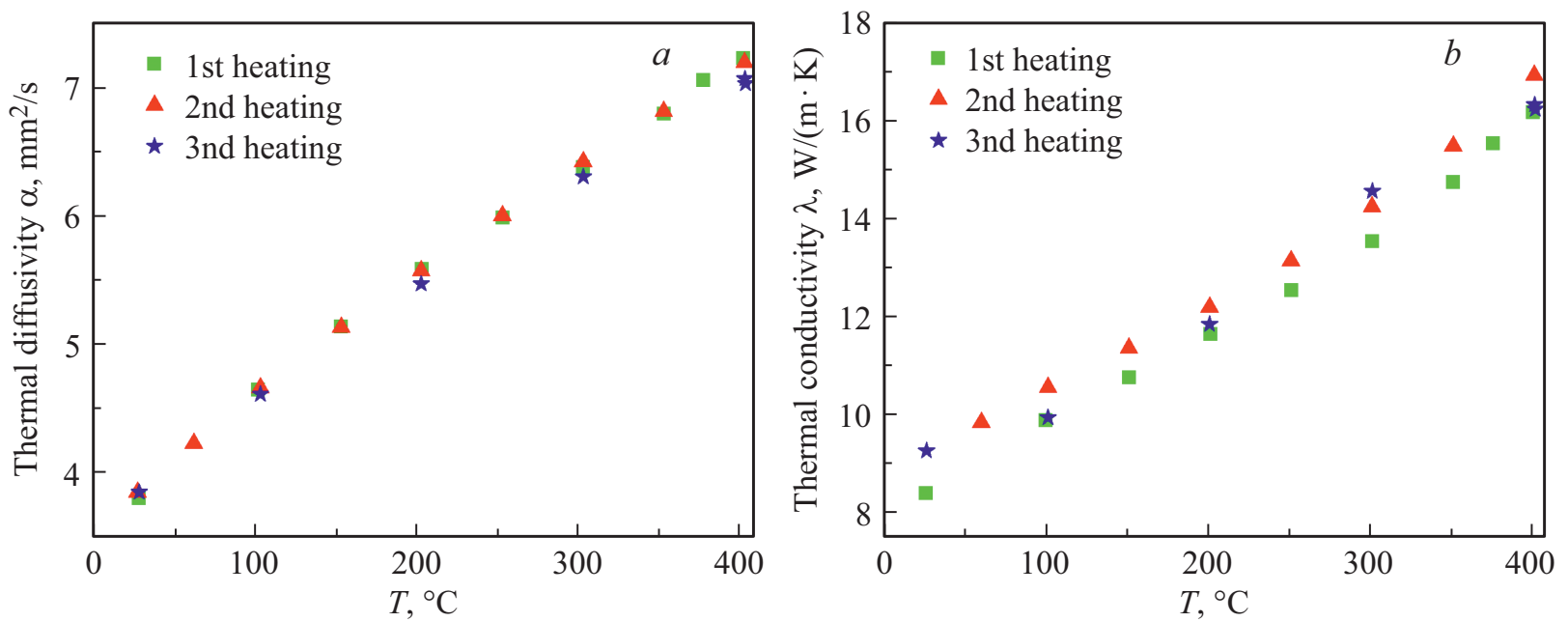

Рис. 2. Температурные зависимости температуропроводности $(a)$ и теплопроводности $(b)$ сплава TiZrHfNb в ходе последовательных циклов нагрева.

полное перемешивание компонентов и достижение однородного состояния материала. Именно об этом свидетельствует уменьшение величины расщепления брэгговских пиков после второго и третьего циклов. Процесс отжига должен сопровождаться укрупнением кристаллитов $(D)$ и снятием напряжений $(\varepsilon)$, возникающих в процессе закалки после дуговой плавки. Однако этого не наблюдается в нашем случае, по крайней мере в течение 
$5 \mathrm{~h}$ отжига (таблица). Никакой тенденции изменения этих параметров $(D$ и $\varepsilon)$ в зависимости от времени отжига не наблюдается. А преимущественная ориентация кристаллитов (текстура), присутствующая в исходном сплаве, даже усилилась настолько, что рефлексы (220) и (321) исчезли уже после первого часа отжига.

Принимая во внимание, что низкотемпературные аллотропные модификации титана, циркония и гафния имеют гексагональную структуру [13] можно ожидать, что при длительных временах термического старения при низких температурах сплав может перейти в двухфазное состояние. С другой стороны, присутствующий в сплаве ниобий, кристаллизующийся только в ОЦК-структуре, может стабилизировать ОЦК-структуру или, по крайней мере, замедлить кинетику перехода состава в двухфазное состояние. Для исследования условий достижения равновесия фазового состояния данного сплава может потребоваться более длительное время.

В контексте возможных приложений жаропрочных ВЭСов важным является исследование их транспортных свойств, в частности теплопроводности. На рис. 2 приведены температурные зависимости температуропроводности $(\alpha)$ и теплопроводности $(\lambda)$ сплава TiZrHfNb, полученные при нагреве от комнатной температуры до $400^{\circ} \mathrm{C}$ (перед изотермической выдержкой) последовательно для каждого цикла термообработки.

Из рис. 2 видно, что значения $\alpha$ и $\lambda$ практически одинаковы для всех трех последовательных циклов нагрева, то есть существенно не изменяются в

[Входе изотермических отжигов. Абсолютные значения указанных величин сравнимы с таковыми в сталях [14]. Такие значения являются допустимыми для сплавов, используемых в качестве материалов для атомной промышленности, основным требованием которых является высокая радиационная стойкость, каковой обладает исследованный нами сплав TiZrHfNb [10].

\section{4. Заключение}

Исследована низкотемпературная стабильность жаропрочного высокоэнтропийного сплава TiZrHfNb c ОЦК-структурой при $T=400^{\circ} \mathrm{C}$. Установлено, что сформировавшееся в результате дуговой плавки неоднородное состояние (сосуществование двух ОЦК-фаз с близким параметром элементарной ячейки) в процессе отжига гомогенизируется. При этом сохраняется высоконапряженное наноструктурированное состояние и усиливается текстура.

Теплопроводность сплава в указанном диапазоне температур изменяется в интервале $8-16 \mathrm{~W} / \mathrm{m} \cdot \mathrm{K}$, что сравнимо по порядку величины с теплопроводностью сталей. Указанные свойства определяют перспективность использования исследованного сплава в качестве материалов для нужд атомной промышленности.

\section{Финансирование работы}

Работа выполнена при финансовой поддержке Российского научного фонда (грант РНФ № 19-73-20053) на оборудовании центра коллективного пользования „Урал-М“.

\section{Конфликт интересов}

Авторы заявляют, что у них нет конфликта интересов.

\section{Список литературы}

[1] Y. Zhang, T.T. Zuo, Z. Tang, M.C. Gao, K.A. Dahmen, P.K. Liaw, Z.P. Lu. Prog. Mater. Sci. 61, 1 (2014).

[2] J. Chen, X. Zhou, W. Wang, B. Liu, Y. Lv, W. Yang, D. Xua, Y. Liu. J. Alloys Comp. 760, 15 (2018).

[3] L. Lilensten, J.P. Couzinié, L. Perriére, J. Bourgon, N. Emery, I. Guillot. Mater. Lett. 132, 123 (2014).

[4] X. Xian, Z. Zhong, B. Zhang, K. Song, C. Chen, S. Wang, J. Cheng, Y. Wu. Mater. Des. 121, 229 (2017).

[5] O.N. Senkov, S.V. Senkova, D.B. Miracle, C. Woodward. Mater. Sci. Eng. A 565, 51 (2013).

[6] Y.D. Wu, Y.H. Cai, T. Wang, J.J. Si, J. Zhu, Y.D. Wang, X.D. Hui. Mater. Lett. 130, 277 (2014).

[7] M. Feuerbacher, T. Lienig, C. Thomas. Scripta Mater. 152, 40 (2018).

[8] S. Marik, M. Varghese, K.P. Sajilesh, D. Singh, R.P. Singh. J. Alloys Comp. 769, 1059 (2018).

[9] F.G. Coury, T. Butler, K. Chaput, A. Saville, J. Copley, J. Foltz, P. Mason, K. Clarke, M. Kaufman, A. Clarke. Mater. Design 155, 244 (2018).

[10] D.J.M. King, S.T.Y. Cheung, S.A. Humphry-Baker, C. Parkin, A. Couet, M.B. Cortie, G.R. Lumpkin, S.C. Middleburgh, A.J. Knowles. Acta Mater. 166, 435 (2019).

[11] Y.D. Wu, Y.H. Cai, T. Wang, J.J. Si, J. Zhu, Y.D. Wang, X.D. Hui. Mater. Lett. 130, 277 (2014).

[12] K.M. Youssef, A.J. Zaddach, C. Niu, D.L. Irving, C.C. Koch. Mater. Res. Lett. 3, 95 (2015).

[13] Н.П. Лякишев. Диаграммы состояния двойных металлических систем: Справочник. Машиностроение, М. (1997). T. $2.1024 \mathrm{c}$.

[14] S.V. Stankus, I.V. Savchenko, A.V. Baginskii, O.I. Verba, A.M. Prokop'ev, R.A. Khairulin. High Temperature 46, 731 (2008).

Редактор Т.Н. Василевская 